\title{
A construção da política de internacionalização para a pós-graduação brasileira
}

\section{The construction of the internationalization policy for Brazilian graduate studies}

\author{
Rosemeri Nunes Feijó* \\ Helgio Trindade*
}

\begin{abstract}
RESUMO
Este artigo tem como foco principal o processo de internacionalização da pós-graduação brasileira. Através da análise dos Boletins Informativos da Capes (InfoCAPES) do período de 1994 a 2002 e dos Planos Nacionais de Pós-Graduação (PNPG) de 1975 a 2011, observa-se que a internacionalização foi gradualmente sendo construída, aparecendo inicialmente como "inserção internacional", como item de avaliação de cursos 6 e 7, até se tornar uma política pública para a pós-graduação brasileira no PNPG 2011-2020. Procura-se demonstrar, também, que algumas questões discutidas desde a década de 1990 ainda hoje são pautas das políticas da Capes para o sistema de pós-graduação, relacionadas à avaliação e à internacionalização.

Palavras-chave: Internacionalização. Educação Superior. Pós-Graduação. Capes. Política Pública.
\end{abstract}

\begin{abstract}
This paper draws on extensive research and documentary analysis of the Coordenação de Aperfeiçoamento de Pessoal de Nível Superior (Capes) [Coordination for the Improvement of Higher Education Personnel] Boletins Informativos da Capes (InfoCAPES) [Informative Bulletins] from 1994 to 2002, and of the Planos Nacionais de Pós-Graduação (PNPG) [Brazilian National Graduate Plans] from 1975 to 2011, to discuss the internationalization process of the Brazilian Graduate Programs. The
\end{abstract}

* Universidade Federal do Rio Grande do Sul. Porto Alegre, Rio Grande do Sul, Brasil. E-mail: rosemerif@hotmail.com-http://orcid.org/0000-0003-0659-5079 E-mail: helgiohtrindade@gmail. com - https://orcid.org/0000-0002-9628-5076 
analysis showed that "internationalization" was a gradual process that appeared initially under the general topic of "international insertion", one of the evaluation items of the higher-ranked programs (graded 6 and 7 in Capes hierarchy). Over the years it started to change into more assertive and well-defined procedures and developed into public policy in the PNPG 2011-2020. The research also demonstrates that some of the issues that have been discussed since the 1990's remain in the Capes agenda regarding the system of evaluation and internationalization.

Keywords: Internationalization. Higher Education. Graduate Programs. Capes. Public Policy.

\section{Introdução}

Este trabalho trata da temática da internacionalização da pós-graduação no Brasil, mais especificamente dos Programas de Excelência Acadêmica (PROEX) em Ciências Sociais. Parte dos dados foi extraída da pesquisa da tese A politica de internacionalização da pós-graduação no Brasil e a prática dos programas PROEX em Ciências Sociais (FEIJÓ, 2019), realizada no Programa de Pós-Graduação em Políticas Públicas da Universidade Federal do Rio Grande do Sul (UFRGS).

A internacionalização é um termo recorrente nos discursos que permeiam as políticas públicas no âmbito da educação, recebendo cada vez mais evidência nas agendas de diferentes países. No Brasil, as universidades são referidas como instituições em busca da internacionalização, sendo essa questão colocada em destaque desde os cursos de graduação, e, sobretudo, nos programas de pós-graduação.

Segundo a autora Jane Knight (2005), a internacionalização é um processo que vai sendo construído e reconstruído ao longo dos anos e se adaptando às mudanças sociais, políticas e culturais. Entende-se que o termo "processo" é utilizado para explicar que a internacionalização ocorre por meio de um esforço contínuo, estando em constante evolução.

Vale ressaltar que a questão internacional esteve presente desde o início da constituição da pós-graduação brasileira, primeiramente com a "educação internacional", depois com os intercâmbios e, após, com os primeiros acordos de cooperação, gerados por ex-alunos formados no exterior. Aos poucos, esse tema foi adquirindo importância até se tornar um vetor-chave na educação pós-graduada, associando-se ao crescimento e à consolidação dos programas, promovendo a visibilidade internacional da ciência brasileira. 
Para Hans de Wit (2013), o sentido de internacionalização, na educação superior, surgiu nos anos de 1990. Antes disso, referido como "educação internacional", era menos um conceito do que um termo abrangente, que buscava englobar toda uma série fragmentada de atividades internacionais pouco relacionadas entre si: o estudo no exterior, a orientação de estudantes estrangeiros, o intercâmbio de estudantes e funcionários entre universidades, assim como o ensino da educação comparada voltado para o desenvolvimento da educação e os estudos de áreas específicas.

Nesta mesma linha, Morosini (2006) cita a dimensão internacional presente no século XX como algo que antecede a educação internacional e é caracterizado por uma fase incidental. Trata a "educação internacional" como uma atividade mais organizada, preferentemente por razões políticas e de segurança nacional, e a "internacionalização" como um processo estratégico posterior à Guerra Fria, ligado à globalização e à regionalização das sociedades e seu impacto na educação superior. Neste caso, a autora corrobora com a ideia de mudança da nomenclatura e das ações estratégicas que atualmente fazem parte da marcha da internacionalização da educação superior no Brasil e no mundo.

No Brasil, nas décadas de 1970 e 1980, a pós-graduação se tornou o locus por excelência da pesquisa acadêmica, fundamentando-se essencialmente no apoio à ampla e diversificada formação de mestres e doutores, com ênfase numa política de bolsas de estudos plenas, de mestrado e doutorado, em países mais desenvolvidos no âmbito científico. A partir desse período, a pós-graduação brasileira passou a desempenhar um papel importante na formação de quadros acadêmicos e de profissionais de alto nível para o desenvolvimento do país.

Entre a segunda metade dos anos de 1990 e segunda metade dos anos de 2000, houve uma mudança na política de formação no nível de pós-graduação stricto sensu. Com a implantação de doutorados de qualidade reconhecida, os pesquisadores passaram a ter sua formação integral no Brasil e a se aperfeiçoar no exterior, recebendo incentivo para a realização de estágios através de programas de doutorado sanduíche e pós-doutorado no exterior (MADEIRA; MARENCO, 2016). O resultado dessa política pode ser apreciado pela atual condição da pós-graduação brasileira, que alcançou excelência em várias áreas do conhecimento, consolidando-se praticamente em todo o território nacional.

Nesse período, também as formas e as relações de pesquisadores e instituições internacionais tiveram avanços com a introdução de sistemas de comunicação inovadores (a internet é certamente o melhor exemplo). Tais mudanças provocaram reflexos importantes no campo da ciência e da tecnologia com a formação de redes internacionais de pesquisa e com novas formas de apoio ao processo de internacionalização da pesquisa científica. 
A relevância desse processo pode ser observada em sua participação nos discursos e políticas voltadas para a educação superior e, especialmente, à pós-graduação brasileira. Tal destaque provoca muitas discussões em torno da necessidade da construção de uma política pública por parte do governo que trate da internacionalização do sistema de educação superior brasileiro. Como não há uma definição consensual na literatura para políticas públicas, é importante esclarecer que, no presente trabalho, assume-se a definição de Souza (2006), que considera que elas podem ser um mecanismo ou conjunto de ações dos governos, ou ainda, uma ação elaborada no sentido de enfrentar um problema público (SECCHI, 2017).

A Capes, através dos seus diversos programas de fomento, tem um papel fundamental na internacionalização do sistema de pós-graduação, confundindo sua trajetória com a da pós-graduação. Suas ações, desde sua criação, foram pautadas por políticas públicas de desenvolvimento do país, bem como pela política pública de pós-graduação, através dos Planos Nacionais de PósGraduação (PNPG), que foram elaborados a partir de 1975, servindo para orientar a institucionalização do Sistema Nacional de Pós-Graduação (SNPG) (KAWASAKI, 2017).

Os Planos Nacionais de Pós-Graduação (PNPG) têm por objetivo subsidiar a formulação e a implementação de políticas voltadas para as áreas de educação, ciência e tecnologia, sendo um dos elementos essenciais na construção e no desenvolvimento do sistema de pós-graduação, juntamente com o Parecer 977/65 (SUCUPIRA et al., 2005), mais conhecido como o Parecer Sucupira, o Parecer 77/69 (BRASIL, 1969), do antigo Conselho Federal de Educação, e a Lei $\mathrm{n}^{\circ}$ 5.540/68 (BRASIL, 1968). No período compreendido de 1974 a 2011, foram elaborados seis PNPGs, embora o IV Plano não tenha sido publicado, não podendo, por isso, ser considerado um documento oficial.

Neste artigo, primeiramente, apresenta-se a análise dos InfoCAPES, boletins informativos editados pela Capes de 1993 a 2002, com o objetivo de verificar como foram aparecendo as primeiras discussões relacionadas à questão internacional na pós-graduação. Cabe salientar que esse boletim era uma publicação técnica, que contava com quatro números por ano e servia como meio de divulgação das atividades da Capes, além de debates e ideias sobre a pós-graduação, incluindo artigos, depoimentos e entrevistas. O boletim também desempenha o papel de espaço de divulgação de documentos oficiais e de políticas para a pós-graduação, servindo como um canal de comunicação entre a comunidade acadêmica e científica.

Na sequência, apresenta-se a análise dos PNPGs, que são os Planos Nacionais de Pós-Graduação elaborados pela Capes desde 1975, com o objetivo de definir diretrizes, estratégias e metas para dar continuidade e 
avançar nas propostas para a política de pós-graduação e pesquisa no Brasil. Com a intenção de verificar a partir de quando a Capes começa a abordar a questão da internacionalização e de que forma ela se apresenta nos Planos, esses documentos foram analisados a fim de extrair as referências em relação à questão internacional.

\section{A questão internacional nos InfoCAPES}

Ao buscar referências sobre a questão internacional nos Boletins da Capes, observa-se que entre os textos analisados, aparece pela primeira vez em 1994 a exigência de "nível internacional", com referência à produção intelectual de um curso de conceito A. Nesse período os programas eram avaliados com os conceitos de A, B, C, D e E, sendo A o conceito mais alto atribuído a um Curso de Pós-Graduação. Naquela época, o "nível internacional" foi a forma encontrada para diferenciar os cursos de pós-graduação, tendo em vista que um grande número desses havia atingido o nível mais alto da escala de avaliação. Destaca-se que, naquele período, já se discutia sobre a criação de um comitê com a participação de consultores internacionais, designado para avaliar os cursos com conceito A, a fim de estabelecer um grau de excelência na escala de conceitos da Capes. Conforme evidenciado nos artigos publicados no InfoCAPES, Maria Andréa Loyola descreve:

Corrigidas as distorções e/ou as discrepâncias de critérios quanto aos cursos A será possível estabelecer no ranking de conceitos da Capes o conceito de Excelência. Esse conceito seria atribuído a um curso após avaliação realizada por um comitê especial que incluiria também consultores internacionais de reconhecida competência na área de conhecimento do curso e seria feita sem periodicidade definida, por demanda do próprio curso (LOYOLA, 1994, p. 5).

Isso também é manifestado nos escritos de Abílio Baeta Neves (1995), no período de sua primeira presidência da Capes (1995 a 2003). Segundo ele, com a intenção de aperfeiçoar o sistema vigente, surgiu a iniciativa de contar com a colaboração de especialistas estrangeiros nas avaliações a fim de medir o desempenho da pós-graduação brasileira, convidando-se consultores externos 
a participarem nos comitês de avaliação em algumas áreas. A preocupação era buscar uma aproximação com os padrões de excelência internacional em "determinadas áreas que já alcançaram a consolidação desejada e que, por seu próprio desenvolvimento, se aproximam fortemente dos padrões internacionais de qualidade acadêmica" (NEVES, 1995, p. 15).

Logo após, em 1997, a Capes convidou sete especialistas em avaliação do ensino superior da Alemanha, Argentina, Canadá, França (2), Irlanda e Estados Unidos, para passar uma semana na Capes, a fim de analisar o modelo brasileiro de avaliação da pós-graduação (SPAGNOLO; CALHAU, 2002). Após o período estipulado para a análise da avaliação, a Comissão Internacional de Avaliação fez várias recomendações, entre as quais se evidencia que a discussão sobre as especificidades das áreas já se fazia presente, sendo salientada pelos avaliadores estrangeiros.

Para Spagnolo (1995), o fato de a Capes não ter direcionado seu sistema de avaliação de forma que os conceitos servissem como parâmetro para uma comparação entre programas nacionais e programas internacionais de excelência acarreta uma série de dificuldades quando se tenta efetuar tal comparação. Além de esta não ser uma tarefa fácil - porque um doutorado com conceito A no Brasil pode ser ou não equivalente aos bons doutorados no exterior -, o objetivo de produzir esse recurso de comparação não fazia parte das preocupações das comissões de avaliação que conceberam o sistema de aferição de notas. Para o autor, era necessário pensar outro formato, que utilizasse os padrões internacionais para poder medir a equivalência a centros internacionais, bem como "adotar como critérios de qualidade padrões internacionais e adotar a autoavaliação como parte integrante do processo" (SPAGNOLO, 1995, p. 13).

Uma das alternativas na construção de critérios de comparabilidade foi a mudança na avaliação, de conceitos (A, B, C, D e E) para notas (1 a 5), em 1990, e após ampliando para (1 a 7) em 1996, a fim de garantir que os conceitos 6 e 7 ficassem restritos a programas comparáveis com aqueles de posição de destaque no cenário internacional. Segundo Spagnolo, "se todos os cursos vierem a atingir os níveis mais altos, projeta-se um cenário onde a utilidade prática da avaliação seria reduzida a zero" (SPAGNOLO, 1995, p. 5).

Logo, a discussão supracitada sobre a participação de consultores estrangeiros para fazer parte das comissões com o intuito de analisar os programas que receberam conceitos 6 e 7 se intensificou. $\mathrm{O}$ entendimento era de que esses consultores poderiam auxiliar na comparação com o nível de excelência internacional, o que também fazia parte das mudanças no sistema de avaliação inseridas na nova sistemática a partir de 1998. 
Nesse mesmo período, o termo "inserção internacional" aparece pela primeira vez no volume 6, número 2, do InfoCAPES de 1998, no âmbito das considerações sobre a nova sistemática de avaliação implantada pela Capes naquele ano, sendo que a avaliação da pós-graduação, pela Capes, tem sido realizada desde 1975, inspirada nos modelos de avaliação norte-americanos. Simultaneamente, tem lugar a ampliação dos conceitos e se passa a avaliar a inserção internacional dos programas. Na primeira referência ao termo, ele aparece relacionado à discussão sobre a avaliação da produção intelectual, mais especificamente sobre a diferença entre o que é produção de nível internacional e produção de circulação internacional. Porém, também se refere ao programa em um aspecto geral, conforme vemos na recomendação a seguir: "é preciso estabelecer parâmetros para medir a inserção internacional dos programas" (FIORIN, 1998, p. 35).

Na avaliação de 1998, referente ao biênio 1996-1997, algumas áreas que demonstraram interesse convidaram consultores/observadores brasileiros atuantes em outras áreas e consultores internacionais atuantes na própria área para colaborar com as comissões, totalizando cinco consultores estrangeiros. Após essa etapa da avaliação, a Capes resolveu testar a "qualidade internacional" dos programas que tinham recebido as notas 6 e 7, as quais haviam sido introduzidas pela primeira vez e referendadas pelo Conselho Técnico Científico (CTC).

Na próxima avaliação, em 2001, a Capes convidou, novamente, observadores estrangeiros para fazerem parte do processo avaliativo, com a preocupação de aperfeiçoar o modelo de avaliação. Os convidados, com algum domínio da língua portuguesa, revezaram-se na Capes para acompanhar a última semana da avaliação do triênio 1998-2000. Dentre as 44 áreas, nem todas solicitaram a participação do especialista estrangeiro, e nem todos os convidados tinham disponibilidade para estarem presentes na semana marcada para a avaliação.

De forma geral, os consultores elogiaram o sistema de avaliação, principalmente em relação ao profissionalismo das comissões e da equipe da Capes: "o sistema de avaliação brasileiro foi considerado de um nível de avaliação muito elevado, em alguns casos até superior ao que era comum encontrar no plano internacional" (SPAGNOLO; CALHAU, 2002, p. 7).

Em que pesem os aspectos negativos da experiência com o novo sistema, os avaliadores levantaram algumas questões, entre elas o excesso de dados coletados e submetidos à análise dos avaliadores. A orientação seria elencar um número seleto de indicadores que efetivamente permitiriam uma avaliação qualitativa dos programas (SPAGNOLO; CALHAU, 2002). Além disso, os especialistas estrangeiros apontaram algumas contradições no que se refere ao próprio significado de internacionalizar: 
Há algo que me intriga na definição de qualidade internacional. Em alguns momentos é definida como acordos de intercâmbio internacional, professores visitantes, etc. E quando se refere a publicações, frequentemente são mencionadas as revistas brasileiras assim classificadas pelo QUALIS. Isso é uma premissa perigosa e, mais grave ainda, retira maiores estímulos para que a interpretação brasileira sobre temas como pós-modernidade, economias do conhecimento ou múltiplas alfabetizações (visual, científica, textual) seja ouvida internacionalmente (SPAGNOLO; CALHAU, 2002, p. 30).

Spagnolo e Calhau (2002) também interrogaram qual seria o propósito de se obter qualidade internacional se as vozes da ciência brasileira não são ouvidas fora do seu território. Essa questão, segundo os autores, deveria ser discutida conjuntamente a uma crítica que questionasse os efeitos de uma forma de avaliação baseada na busca por um padrão internacional como parte de um projeto maior para a pós-graduação, no qual a preocupação com a qualidade internacional se sobrepõe à visibilidade de bons programas locais.

A crítica à internacionalização também ocorria por outros caminhos e em diferentes momentos. Por exemplo, Fensterseifer (2001) argumenta que o processo de internacionalização que vinha ocorrendo nas pós-graduações brasileiras, de um modo geral, produzia-se de fora para dentro, sendo direcionado pelo mercado e por influências internacionais. Além dele, também Balbachevsky (2005) questiona se a lógica empresarial evidente em muitos casos não tem sido perversa em relação aos interesses acadêmicos nacionais.

Identifica-se que algumas sugestões da década de 1990 foram implantadas nos anos de 2000, como é o caso da consideração de Spagnolo (1995), na qual ele diz:

uma outra perspectiva, mais ousada, é de abrir o sistema para bolsas de estudo de graduação no exterior, sobretudo em áreas prioritárias como a tecnológica, nos moldes do doutorado "sanduíche" ou do Projeto Erasmus - que permite aos universitários europeus passar um período de sua formação em outro país. Candidatos jovens (de 19-20 anos), períodos curtos e bolsas mais modestas permitiriam o envio de milhares de graduandos para estudar no exterior. Tais experiências oxigenariam os cursos de graduação com a volta de alunos mais críticos e enriquecidos com novas experiências de aprendizagem acadêmica (SPAGNOLO, 1995, p. 14). 
Essa observação de Spagnolo vai ao encontro de um programa do governo federal criado no governo Dilma Rousseff, lançado no dia 26 de julho de 2011, o Programa Ciência sem Fronteiras, que foi considerado, até então, a maior política de internacionalização da educação superior com foco na mobilidade de alunos de graduação. O projeto previa a concessão de até 65 mil bolsas no período de quatro anos. A iniciativa foi fruto de um esforço conjunto do Ministério da Ciência e Tecnologia (MCT) e do Ministério da Educação (MEC), por meio de suas respectivas instituições de fomento - CNPq e Capes - e secretarias de Ensino Superior e de Ensino Tecnológico do MEC. Entre seus objetivos estavam a promoção, a consolidação, a expansão e a internacionalização da ciência e da tecnologia, da inovação e da competitividade brasileira por meio do intercâmbio de alunos de graduação e pós-graduação e da mobilidade internacional (MAUÉS; BASTOS, 2017). Em um artigo de Miranda e Stallivieri (2017), no qual tratam da existência de políticas para a internacionalização das IES brasileiras, os autores constataram que foi

mais pontualmente, a partir do PNPG 2011-2020 e do documento do Programa Ciência sem Fronteiras, lançado em 2011 pelo Governo Federal, que a internacionalização da educação superior aparece como um desejo por parte do governo brasileiro de forma mais pontual (MIRANDA; STALLIVIERI, 2017, p. 595).

O programa, nesse formato mais abrangente, passou a financiar apenas as modalidades de pós-graduação a partir de 2014. Apesar da curta duração, foi uma iniciativa notável por ter sido a primeira política de internacionalização desenvolvida com base na graduação, encerrando suas atividades em abril de 2017.

Em novembro de 2017 a Capes lançou o Programa Institucional de Internacionalização - Capes-Print. Segundo Barros et al. (2020), o programa

sinalizou o direcionamento das estratégias da Capes para o fomento de ações inerentes às políticas de internacionalização do ensino das IES brasileiras por meio do stricto sensu, priorizando desta forma esse segmento do ensino, e não mais diretamente os programas de graduação, como o extinto Ciência sem Fronteiras (BARROS et al., 2020, p. 9). 
As implicações do Capes-Print bem como suas finalidades serão exploradas mais adiante, na seção “A internacionalização como política no PNPG 2011-2020”.

\section{A questão internacional nos Planos Nacionais de Pós-Graduação}

O fortalecimento da pós-graduação no país já se mostrava presente nos anos de 1970, sendo mais explícito a partir da elaboração dos Planos Nacionais de Pós-Graduação. Em sua atuação como agência voltada para a pós-graduação, a Capes desempenha um papel fundamental - desde a sua fundação até os dias de hoje - na formulação de políticas para a pós-graduação brasileira. Os PNPGs imprimiram uma direção para a consolidação e a institucionalização da pós-graduação por meio de diagnósticos e da formulação de metas e ações. Ao mesmo tempo, a Capes conduz acompanhamentos anuais e avaliações trienais - passando a quadrienais em 2017 - de desempenho de todos os programas que integram o Sistema Nacional de Pós-Graduação.

A abordagem conduzida pela agência é orientada para a qualidade dos programas como um todo, pois os resultados dos monitoramentos e avaliações influenciam o financiamento de tais programas. No quadro a seguir, mostramos as principais referências à questão internacional nos PNPGs.

QUADRO 1 - PERFIL DOS PLANOS NACIONAIS DE PÓS-GRADUAÇÃO (PNPG) - CAPES: MISSÃO E INSERÇÃO INTERNACIONAL (1975-1979 A 2011-2020)

\begin{tabular}{|c|c|c|}
\hline PNPG & Missão Principal & $\begin{array}{l}\text { Evolução da Inserção } \\
\text { Internacional }\end{array}$ \\
\hline $\begin{array}{c}\text { I PNPG } \\
(1975-1979)\end{array}$ & $\begin{array}{l}\text { Institucionalização o sistema de Pós- } \\
\text { Graduação através da capacitação } \\
\text { dos docentes das universidades, } \\
\text { formando o primeiro contingente } \\
\text { de pesquisadores e especialistas em } \\
\text { âmbito federal. }\end{array}$ & $\begin{array}{l}\text { “[...] devem ser programados } \\
\text { intercâmbios com instituições } \\
\text { estrangeiras" (BRASIL, 1975, p. 4). }\end{array}$ \\
\hline $\begin{array}{c}\text { II PNPG } \\
(1982-1985)\end{array}$ & $\begin{array}{l}\text { Preocupação com o desempenho e } \\
\text { a qualidade tendo como instrumento } \\
\text { a avaliação, que já existia em estado } \\
\text { embrionário desde } 1976 \text { e que será } \\
\text { então aperfeiçoada e institucionalizada. } \\
\text { Mantém as ênfases do plano anterior } \\
\text { e acrescenta a formação de recursos } \\
\text { humanos qualificados. }\end{array}$ & $\begin{array}{l}\text { "[...] atualização [dos docentes] } \\
\text { através da participação em congressos, } \\
\text { seminários, encontros e intercâmbios" } \\
\text { (BRASIL, 1982, p. 179). }\end{array}$ \\
\hline
\end{tabular}

(continua) 


\begin{tabular}{|c|c|c|}
\hline PNPG & Missão Principal & $\begin{array}{l}\text { Evolução da Inserção } \\
\text { Internacional }\end{array}$ \\
\hline $\begin{array}{l}\text { III PNPG } \\
(1986-1989)\end{array}$ & $\begin{array}{l}\text { Desenvolvimento da pesquisa pelas } \\
\text { universidades por meio da integração } \\
\text { dessa pesquisa com o setor produtivo, } \\
\text { visando o desenvolvimento nacional. }\end{array}$ & $\begin{array}{l}\text { Produção de um padrão internacional } \\
\text { para tornar o país internacionalmente } \\
\text { competitivo; reforço aos programas } \\
\text { de cooperação técnica internacional; } \\
\text { ampliação de projetos de cooperação } \\
\text { internacional; apoio a revistas } \\
\text { científicas brasileiras de padrão } \\
\text { internacional (BRASIL, 1986, p. } 199 \text {, } \\
\text { 205, 206, 207, 211). }\end{array}$ \\
\hline $\begin{array}{l}\text { IV PNPG } \\
(1996-2004)\end{array}$ & $\begin{array}{l}\text { Este não foi promulgado, mas } \\
\text { suas diretrizes foram adotadas } \\
\text { pela Capes. Caracterizou-se pela } \\
\text { ênfase na expansão do sistema, na } \\
\text { diversificação do modelo de pós- } \\
\text { graduação, na introdução de mudanças } \\
\text { no processo de avaliação e na inserção } \\
\text { internacional do Sistema Nacional de } \\
\text { Pós-Graduação (SNPG). }\end{array}$ & $\begin{array}{l}\text { Flexibilização do modelo de pós- } \\
\text { graduação, aperfeiçoamento do } \\
\text { sistema de avaliação e a ênfase na } \\
\text { internacionalização (BRASIL, } \\
\text { 2011, p. 16). }\end{array}$ \\
\hline $\begin{array}{c}\text { PNPG } \\
(2005-2010)\end{array}$ & $\begin{array}{l}\text { Aprimoramento do processo de } \\
\text { avaliação qualitativa da pós-graduação } \\
\text { (conceito de nucleação, revisão do } \\
\text { Qualis e introdução do PROEX); } \\
\text { preocupação com a solidariedade } \\
\text { entre os cursos e seu impacto social; } \\
\text { expansão da cooperação internacional; } \\
\text { combate às assimetrias; formação de } \\
\text { recursos humanos para a inovação } \\
\text { tecnológica no mundo globalizado e } \\
\text { competitivo; ênfase na formação de } \\
\text { docentes para todos os níveis de ensino, } \\
\text { bem como de quadros técnicos via } \\
\text { mestrado profissional para os setores de } \\
\text { serviços público e privado; expansão do } \\
\text { sistema de pós-graduação. }\end{array}$ & $\begin{array}{l}\text { Políticas de cooperação internacional, } \\
\text { periódicos de circulação internacional, } \\
\text { processo de integração com a } \\
\text { comunidade científica internacional } \\
\text { e inserção internacional da Pós- } \\
\text { Graduação. }\end{array}$ \\
\hline
\end{tabular}

(continua) 


\begin{tabular}{|c|c|c|}
\hline PNPG & Missão Principal & $\begin{array}{c}\text { Evolução da Inserção } \\
\text { Internacional }\end{array}$ \\
\hline $\begin{array}{c}\text { PNPG } \\
(2011-2020)\end{array}$ & $\begin{array}{l}\text { Definição de novas estratégias, } \\
\text { diretrizes e metas para dar continuidade } \\
\text { e avançar nas propostas para a política } \\
\text { de Pós-Graduação e Pesquisa no Brasil. } \\
\text { A exemplo dos Planos anteriores, } \\
\text { também neste a busca da Internacio- } \\
\text { nalização continuará sendo uma das } \\
\text { metas maiores do sistema (BRASIL, } \\
\text { 2011, p. 21). } \\
\text { O Plano } 2011 \text { - } 2020 \text { levará em } \\
\text { consideração o legado dos planos } \\
\text { anteriores, propondo a continuidade do } \\
\text { crescimento com qualidade do SNPG, } \\
\text { e incorporará novas ações e políticas. }\end{array}$ & $\begin{array}{l}\text { Cap. } 11 \text { - Internacionalização da } \\
\text { Pós-Graduação e a Cooperação } \\
\text { Internacional (presença internacional } \\
\text { da ciência e da tecnologia brasileira) } \\
\text { Sugestões: } \\
\text { - envio de mais estudantes ao exterior } \\
\text { para fazerem doutorado; } \\
\text { - estímulo à atração de mais alunos e } \\
\text { pesquisadores visitantes estrangeiros; } \\
\text { - aumento do número de publicações } \\
\text { com instituições estrangeiras. }\end{array}$ \\
\hline
\end{tabular}

Fonte: Elaborado pela autora com base nas informações dos PNPGs.

As informações destacadas no quadro demonstram as metas que foram elaboradas para a pós-graduação em cada um dos planos. Cabe mencionar que cada um foi concebido dentro da conjuntura política e econômica específica em que se encontrava o país (FRANÇA, 2014).

No I PNPG (1975-1979), foram definidas como principais atribuições da Capes: orientação, implantação, acompanhamento e avaliação dos programas de capacitação docente e de recursos humanos. Nesse período, o foco era a institucionalização do sistema de pós-graduação e por isso suas diretrizes eram orientadas para a capacitação dos docentes. Cabe salientar que, dentro da sua vigência, foi estabelecida, em 1976, a avaliação da pós-graduação stricto sensu (Capes, 2002). O I PNPG apresentou um diagnóstico da pós-graduação até 1975 e as diretrizes para reparar as distorções. Porém, o seu foco era voltado à formação acadêmica de docentes das universidades, formando o primeiro contingente de pesquisadores e especialistas no âmbito federal.

Em relação à questão internacional, nesta primeira edição, o texto do Plano fez referência ao aspecto da mobilidade internacional docente, ocorrendo através dos intercâmbios. Esse é um termo bastante utilizado também no sentido de trocas, sempre relativo ao fluxo de pessoas nas diferentes direções. Portanto, não se refere apenas à troca de conhecimento, mas ao deslocamento físico de indivíduos entre instituições dentro do país, a fim de implantar e/ ou consolidar cursos; assim como entre cursos, departamentos e unidades da 
universidade: "intercâmbio de pessoa e de grupos de trabalho interdepartamentais e interinstitucionais" (BRASIL, 1975, p. 23). Essa modalidade também é contemplada nos três primeiros Planos Nacionais de Pós-Graduação.

Nos dois primeiros PNPGs, que compreendem o período de 1975 a 1985, havia referência aos intercâmbios, como pode ser observado no I PNPG: "intercâmbios com instituições estrangeiras" (BRASIL, 1975, p. 4, grifo nosso). O objetivo dessa edição do Plano com relação aos intercâmbios era de criar ou consolidar os cursos, prevendo a absorção de pesquisadores que estavam realizando o doutorado no exterior e a presença de professores estrangeiros. A ênfase era para os convênios e intercâmbios de longo prazo para iniciar ou fortalecer grupos de ensino e pesquisa nacionais, procurando alcançar uma reciprocidade efetiva. Cabe ressaltar que durante o período de vigência deste PNPG (1975-1979), foi assinado, em 1978, o termo de compromisso que instituiu o Acordo do Comitê Francês de Avaliação da Cooperação Universitária com o Brasil (Cofecub), entre o Brasil e a França, que continua sendo um dos acordos mais amplos e duradouros entre os dois países.

O II PNPG (1982-1985) fixa objetivos, prioridades e diretrizes que compõem a política do Ministério da Educação e Cultura para a área da pós-graduação, em sintonia com as orientações do III Plano Nacional de Desenvolvimento - III PND, lançado no governo do presidente João Figueiredo. Um dos objetivos básicos do II PNPG é o aumento da qualidade dos profissionais formados e das pesquisas realizadas, sendo que, para isso, o plano traz os mecanismos de acompanhamento e avaliação. Assume-se como prioridade o aperfeiçoamento do sistema de avaliação da pós-graduação, com o objetivo de melhorar a qualidade, que se considerava estar sendo prejudicada pela expansão quantitativa do SNPG.

O III PNPG (1986-1989) foi elaborado no mesmo período do I Plano Nacional de Desenvolvimento - PND, da Nova República, na presidência de José Sarney, momento em que a tendência era a conquista da autonomia científica nacional, ideia que já fazia parte do Plano anterior. A Nova República instalou-se com o compromisso de mudar a vida política, econômica e social do país. O I Plano Nacional de Desenvolvimento da Nova República (I PNDNR) para o período 1986-89 é parte desse processo de mudança. Esse é um plano de reformas, de crescimento econômico e de combate à pobreza. Todos os programas e recursos definidos dirigem-se para essas três metas estratégicas. Colocar em prática esse projeto de autonomia implicava necessariamente um número suficiente de cientistas e, como o país ainda não tinha esse contingente, seria necessário aumentar a formação de recursos humanos de alto nível. Quanto a esse quesito, segundo dados da Capes, o número de doutores titulados entre os anos de 1989 e 1990 aumentou de 1.047 para 1.302, e o número de mestres, de 4.727 para 5.737 (BRASIL, 2005, p. 29-30). 
Ao observarmos a questão da internacionalização neste III Plano, as referências aos programas parecem norteá-los para qualidades mais consistentes e sistemáticas: "produção de padrão internacional, tornar o país internacionalmente competitivo, reforço aos programas de cooperação técnica internacional, ampliar projetos de cooperação internacional, apoiar revistas brasileiras de padrão internacional" (BRASIL, 1986, p. 206). A importância da Cooperação Técnica Internacional é enfatizada como forma de possibilitar o "intercâmbio de docentes e pesquisadores com seus pares de instituições no exterior" (BRASIL, 1986, p. 206), constituindo-se em uma maneira de articulação com a cooperação nacional, passando essa a ser mais enfatizada entre as instituições. De seu lado, os intercâmbios são estimulados através da participação docente e de pesquisadores em reuniões científicas no país e no exterior.

Um dos propósitos, em particular, chama a atenção nesse Plano: "tornar o país internacionalmente competitivo". O entendimento é que essa competição deve ocorrer através do ensino e da pesquisa, como mostra uma das medidas a serem tomadas para aumentar a eficiência na formação: a "capacitação no exterior, de acordo com as necessidades de melhoria e renovação dos cursos de pós-graduação, bem como de fortalecimento de áreas novas ou carentes" (BRASIL, 1986, p. 205), aumentando a capacidade interna de formação de cientistas e promovendo a internacionalização da produção científica do país. Essas orientações apontam para a importância atribuída à pós-graduação e parecem confirmar a demanda crescente por pessoal qualificado.

Na sequência, a elaboração do IV PNPG (1996-2004) foi acompanhada de discussões e reuniões, desenvolvidas, em grande parte, no período dos dois governos do presidente Fernando Henrique Cardoso. Mesmo não tendo sido promulgado e não tendo se constituído efetivamente como um Plano devido a restrições orçamentárias e à falta de articulação entre as agências nacionais de fomento, a Capes, ainda assim, seguiu suas orientações.

A ênfase do IV PNPG voltava-se à introdução de mudanças no processo de avaliação e na inserção internacional do SNPG (BRASIL, 2011), porém, apesar da importância das suas diretrizes, o IV PNPG não pode ser considerado como um documento oficial por não ter sido publicado. Isso, porém, não tira a importância de suas orientações, que foram colocadas em prática.

Também se coloca como mudança importante nesse período o novo modelo de avaliação formulado pela Capes. Adotado para o biênio 19961997, direciona o foco da avaliação para a pesquisa e a produção científica, deixando-se de focar prioritariamente a docência. É também sintomático que, a partir de 1998, o termo "inserção internacional" passe a ser um indicador de qualidade na avaliação trienal da Capes, mudança que ocorre em um período marcado por grandes questionamentos e profundas transformações na educação superior na esfera global. 
No ano de 2005, a Capes retoma a publicação dos Planos Nacionais de Pós-Graduação, porém não seguindo a nomenclatura alfanumérica usada até então (PNPG I, II, III, IV), passando a denominar o Plano pelo seu período de vigência, como se observa já no PNPG 2005-2010. Nesse momento, a pósgraduação brasileira se encontra em outro patamar, mais consolidada e com um processo de avaliação mais abrangente, no qual a inserção internacional já vinha tomando parte como critério de análise dos programas. Segundo o PNPG 20052010, "a pós-graduação brasileira é uma das melhores em todo o hemisfério Sul, e tem contribuído de forma decisiva para o desenvolvimento do país" (BRASIL, 2005, p. 49). Entre outros avanços, o Plano reitera a avaliação brasileira como reconhecida e respeitada internacionalmente e promove, também, a introdução do Programa de Excelência Acadêmica (PROEX) e a revisão do Qualis, que é o conjunto de procedimentos utilizados pela Capes para estratificação da qualidade da produção intelectual dos programas de pós-graduação, sendo que desde 2009 não é mais realizada a qualificação de eventos, apenas de periódicos e livros.

No PNPG 2005-2010, a cooperação internacional ganha maior destaque, sendo contemplada com um item específico sobre o tema, denominado de Políticas de Cooperação Internacional e de Formação de Recursos Humanos no Exterior. Observa-se a ênfase dada às políticas de cooperação internacional, periódicos de circulação internacional, processo de integração com a comunidade científica internacional, inserção internacional da pós-graduação. O destaque à cooperação internacional já ocorrera em planos anteriores, porém, nunca de forma tão explícita como nesta menção, em que a "cooperação internacional" e a "inserção internacional" aparecem como metas.

Em um depoimento proferido em 2002, Abílio Afonso Baeta Neves, presidente da Capes (1995-2002), fala de um aspecto importante que foi mais tarde estipulado pelo Plano 2005-2010, que tinha relação com o "inevitável incremento da internacionalização da nossa pós-graduação, ou seja, a cooperação internacional passava a ter peso muito importante em todos os planos, até mesmo no plano da avaliação" (NEVES, 2002, p. 6). Até o PNPG 2005-2010, a internacionalização vinha se apresentando nos textos dos planos de várias formas, no entanto, sem a utilização desse termo específico, mas com referências a ações de cooperação internacional, como as que farão parte do processo de internacionalização. A internacionalização, posteriormente, aparecerá como um item específico do PNPG que abrange o período de 2011-2020, passando a ser uma política para a pós-graduação, apoiada pelo incremento da cooperação internacional. 


\section{A internacionalização como política no PNPG 2011-2020}

Após a retomada da elaboração dos Planos pela Capes, e principalmente no último, que compreende o período de mudança da avaliação para quadrienal, a internacionalização se tornou efetivamente uma política para a pós-graduação, tendo sido incorporada também pelo Plano Nacional de Educação (PNE), que foi desenvolvido após a definição do atual Plano (PNPG 2011-2020). Na apresentação deste último é destacada a incorporação das diretrizes da pósgraduação pelo PNE 2014-2024 em elaboração:

O Plano Nacional de Pós-Graduação (PNPG) 2011-2020 tem como objetivo definir novas diretrizes, estratégias e metas para dar continuidade e avançar nas propostas para política de pós-graduação e pesquisa no Brasil. Paralelamente a este Plano, está sendo elaborado o novo Plano Nacional de Educação (PNE). De fato, pela primeira vez, um plano nacional de educação contemplará as metas da pós-graduação, isso porque o PNPG será parte integrante do PNE (BRASIL, 2011, p. 1).

Segundo Silva Júnior e Kato (2016), a condução política dessas recomendações se encontra em pleno processo de desenvolvimento. A exemplo disso, pela primeira vez o PNE (2014-2024) contempla diretrizes referentes à pós-graduação, com metas e estratégias direcionadas para a política de internacionalização, demonstrando a relevância que tal política adquiriu nos últimos anos.

No momento da elaboração desse Plano, o Brasil estava sendo visto como um país emergente e promissor, com protagonismo no cenário internacional, período este que tinha iniciado com o governo Lula, em 2003. O país estava passando por várias mudanças e a perspectiva era de que viesse a vivenciar ainda outras transformações profundas, em vários setores da sociedade, incluindo-se aí o sistema educacional e, dentro dele, o ensino superior. Essa expectativa e o panorama que vinha se desenvolvendo, inclusive de um maior acesso à educação em todos os níveis, transpareciam também com o objetivo de elevar a pós-graduação brasileira a um novo patamar no cenário internacional (BRASIL, 2011, p. 16). 
No capítulo sobre Internacionalização da Pós-Graduação e a Cooperação Internacional do PNPG 2011-2020, a internacionalização está relacionada ao desenvolvimento da pesquisa e produção científica e à sua relação com as ações e mecanismos de cooperação internacional. Tendo em vista que o Brasil estava sendo cotado para chegar à $5^{a}$ economia mundial, a sua inserção internacional através da pesquisa e produção científica seria vital para alcançar esse patamar (SILVA JÚNIOR; KATO, 2016).

Em 2011, na vigência desse Plano, foi lançado o Programa de Doutorado Sanduíche no Exterior (PDSE), fazendo parte da proposta de fortalecimento da internacionalização, em substituição ao Programa de Doutorado Sanduíche Balcão e ao Programa de Doutorado no País com Estágio no Exterior (PDEE). A mudança tinha como objetivo ampliar o número de bolsas concedidas às Instituições de Ensino Superior (IES) e dar maior agilidade ao processo de implantação das bolsas de estágio de doutorado no exterior. A modalidade de doutorado sanduíche no exterior passou também a ser realizada dentro do Capes-Print, a partir de sua criação em 2017.

Tal programa, conforme já abordado, caracteriza-se por uma concepção mais abrangente no que diz respeito à política de internacionalização. Ou seja, demonstra um foco maior no pensamento estratégico institucional e também uma expansão da própria noção de internacionalização. A preocupação da Capes com os indicadores internacionais de produção acadêmica demonstra uma mudança de abordagem no que diz respeito às políticas de internacionalização, que até então eram centradas na mobilidade acadêmica de saída, cujo auge se deu com o programa Ciência sem Fronteiras (OLIVEIRA, 2019).

Em dezembro de 2020 a Diretoria de Relações Internacionais (DRI) da Capes lançou o Guia para Aceleração da Internacionalização Institucional: Pós-Graduação Stricto Sensu. Conforme publicação no portal da Capes, esse guia toma como base três indicadores comuns aos rankings internacionais: alta concentração de estudantes e professores talentosos, rico ambiente de aprendizado e pesquisas de alto impacto.

É destacado também que o objetivo principal seja apoiar a gestão de projetos contemplados no Print. Tal guia demonstra que o modelo de designação do governo federal em projeto de internacionalização acentua as desigualdades, uma vez que privilegia instituições com experiências em ações voltadas para o desenvolvimento da internacionalização, a ver os programas PROEX, com conceitos 6 e 7 na avaliação da Capes. 
Para além, destacam-se outros obstáculos que dificultam a efetivação de uma política pública de internacionalização, como o desmonte orçamentário e a instabilidade institucional que tem caracterizado a gestão do governo Bolsonaro (2019-2022). Tais ações formalizam a restrição do fomento à pesquisa e, consequentemente, a desestabilização das instituições (OLIVEIRA, 2019).

A internacionalização ainda se constitui em um desafio para as instituições, uma vez que, para se efetivar necessita estar integrada a um planejamento estratégico nacional. Contudo, de acordo com Neves e Barbosa (2020), tal processo constitui-se em um conjunto de oportunidades, mais ou menos exploradas, que potencializam o fortalecimento da qualidade do sistema de pós-graduação e de suas contribuições para uma maior equidade.

\section{Considerações finais}

A análise do material levantado para a presente pesquisa indica que a internacionalização da pós-graduação brasileira foi sendo estabelecida aos poucos, desde a sua constituição, até se tornar uma política pública no PNPG 2011-2020. Trata-se de um processo que foi construído ao longo da trajetória da pós-graduação, com o aporte da Capes, através dos PNPGs e do processo avaliativo que foi estabelecendo diretrizes para os Programas. Ao analisar os Boletins da Capes - os InfoCAPES - conclui-se que a questão internacional esteve presente principalmente relacionada à excelência acadêmica. Isso se evidencia na atenção dada pela Capes em verificar se os programas de pósgraduação melhor avaliados poderiam ser comparáveis com programas em nível internacional. Tal esforço incluiu experiências que contaram com a presença de consultores estrangeiros nos anos de 1990 e início dos anos 2000 para avaliar a pós-graduação brasileira.

Observa-se, como um todo, que a colaboração internacional esteve presente mais ou menos explicitamente como uma das principais formas de levar a ciência brasileira para o exterior e, principalmente, promover a internacionalização.

Nos Planos anteriores ao IV PNPG, percebe-se que os intercâmbios e a cooperação internacional eram as ações mais estimuladas e valorizadas. Contudo, a partir daí o tema se intensificou e se passou a falar claramente em inserção internacional, a ponto de, no último PNPG (2011-2020), a palavra "internacionalização" ter sido mencionada 77 vezes e de ter sido dedicado um capítulo inteiro ao tema. 
Embora a pós-graduação pareça ter avançado no processo de internacionalização, de forma independente da instituição, uma nova direção parece ter sido sinalizada com a mudança implementada para a avaliação quadrienal de 2021, incluindo a autoavaliação e o planejamento estratégico. Isso sugere que houve a intenção da Capes de vincular o planejamento estratégico dos programas de pós-graduação aos de suas instituições.

Ainda em relação à Capes, pode-se observar que, assim como a própria internacionalização, a avaliação dos programas também tem sido um processo em constante evolução, e que necessariamente se adapta a eventuais demandas, como a inclusão e diversificação de critérios relativos à inserção internacional.

Embora, como fora abordado, a Capes, no decorrer dos anos, tenha se empenhado em estabelecer padrões de qualidade através da participação de consultores estrangeiros nas avaliações, afirmado o objetivo de comparar a pósgraduação brasileira com cursos internacionais e, apesar das áreas entenderem a sua necessidade, ainda não foi desenvolvido um mecanismo que consiga realizar essa aferição de forma plenamente satisfatória.

\section{REFERÊNCIAS}

BALBACHEVSKY, Elizabeth. A pós-graduação no Brasil: novos desafios para uma política bem-sucedida. In: BROCK, Colin; SCHWARTZMAN, Simon (org.). Os desafios da educação no Brasil. Rio de Janeiro: Nova Fronteira, 2005. p. 275-304.

BARROS, Manoel Joaquim Fernandes de et al. A internacionalização da educação por instituições de ensino superior. Revista de Desenvolvimento Econômico, Salvador, v. 1, n. 45 , p. 365-393, 2020.

BRASIL. Presidência da República. Lei no 5.540, de 28 de novembro de 1968. Fixa normas de organização e funcionamento do ensino superior e sua articulação com a escola média, e dá outras providências. Diário Oficial da União, Brasília, DF, 3 dez. 1968.

BRASIL. Ministério da Educação e Cultura. Conselho Federal de Educação. Parecer n ${ }^{\circ}$ 77/69. Normas do credenciamento dos cursos de pós-graduação. Documenta, Brasília, DF, n. 98, p. 128-132, 1969.

BRASIL. Ministério da Educação. Coordenação de Aperfeiçoamento de Pessoal de Nível Superior (CAPES). I Plano Nacional de Pós-Graduação (PNPG) 1975-1979. Brasília, DF: CAPES, 1975. 
BRASIL. Ministério da Educação. Coordenação de Aperfeiçoamento de Pessoal de Nível Superior (CAPES). II Plano Nacional de Pós-Graduação (PNPG) 1982-1985. Brasília, DF: CAPES, 1982.

BRASIL. Ministério da Educação. Coordenação de Aperfeiçoamento de Pessoal de Nível Superior (CAPES). III Plano Nacional de Pós-Graduação (PNPG) 1986-1989. Brasília, DF: CAPES, 1986.

BRASIL. Ministério da Educação. Coordenação de Aperfeiçoamento de Pessoal de Nível Superior (CAPES). Plano Nacional de Pós-Graduação (PNPG) 2005-2010. Brasília, DF: CAPES, 2005.

BRASIL. Ministério da Educação. Coordenação de Aperfeiçoamento de Pessoal de Nível Superior (CAPES). Plano Nacional de Pós-Graduação (PNPG) 2011-2020. Brasília, DF: CAPES, 2011.

BRASIL. Ministério da Educação. Coordenação de Aperfeiçoamento de Pessoal de Nível Superior (CAPES). Diretoria de Relações Internacionais (DRI). Guia para Aceleração da Internacionalização Institucional: Pós-Graduação Stricto Sensu. Brasília, DF: CAPES, dez. 2020. Disponível em: https://www.gov.br/capes/pt-br/centrais-deconteudo/23122020_Guia_para_Acelerao_da_Internacionalizao_Institucional.pdf. Acesso em: 31 maio 2021.

DE WIT, Hans. Internationalisation of Higher Education: An Introduction on the Why, How and What. In: DE WIT, Hans (org.). An Introduction to Higher Education Internationalisation. Milan: Centre for Higher Education Internationalisation (CHEI), Universitá Cattolica del Sacro Cuore, 2013. p. 13-46.

FEIJÓ, Rosemeri Nunes. A politica de internacionalização da pós-graduação no Brasil e a prática dos programas PROEX em Ciências Sociais. 2019. 196f. Tese (Doutorado em Políticas Públicas) - Universidade Federal do Rio Grande do Sul, Porto Alegre, 2019.

FENSTERSEIFER, Jaime. O imbróglio dos "fora da sede". INFOCAPES - Boletim Informativo da CAPES, Brasília, DF, v. 9, n. 4, p. 117-120, out./dez. 2001.

FIORIN, José Luís. Considerações em torno do novo processo de avaliação. INFOCAPES - Boletim Informativo da CAPES, Brasília, DF, v. 6, n. 2, p. 33-35, abr./jun. 1998.

FRANÇA, Indira Alves. Avaliação da Capes e Gestão de Programas de Excelência na Área da Educação. 2014. 249 f. Tese (Doutorado em Educação) - Pontifícia Universitária Católica do Rio de Janeiro, Rio de Janeiro, 2014.

KAWASAKI, Bruno César. Critérios de avaliação Capes para Programas de PósGraduação. Revista Adusp, São Paulo, n. 60, p. 102-117, 2017.

KNIGHT, Jane. Un modelo de internacionalización: respuesta a nuevas realidades y retos. In: DE WIT, Hans; JARAMILLO, Isabel Cristina; GACEL-AVILA, Jocelyne; KNIGHT, Jane (org.). Educación Superior en América Latina: la dimensión internacional. Bogotá: Banco Mundial en coedición con Mayol Ediciones, 2005. p. 1-38. 
LOYOLA, Maria Andréa Rios. Perfil dos cursos A, cursos novos e outras novidades. INFOCAPES - Boletim Informativo da CAPES, Brasília, v. 2, n. 3, p. 5-6, jul./set. 1994.

MADEIRA, Rafael Machado; MARENCO, André. Os desafios da internacionalização: mapeando dinâmicas e rotas da circulação internacional. Revista Brasileira de Ciência Política, Brasília, n. 19, p. 47-74, 2016.

MAUÉS, Olgaíses Cabral; BASTOS, Robson dos Santos. Políticas de internacionalização da Educação Superior: o contexto brasileiro. Educação, Porto Alegre, v. 40, n. 3, p. 333-342, set./dez. 2017.

MIRANDA, José Alberto Antunes de; STALLIVIERI, Luciane. Para uma política pública de internacionalização para o ensino superior no Brasil. Avaliação: Revista da Avaliação da Educação Superior, Campinas, v. 22, n. 3, p. 589-613, dez. 2017.

MOROSINI, Marília Costa. Estado do conhecimento sobre internacionalização da educação superior: conceitos e práticas. Educar em Revista, Curitiba, n. 28, p. 107-124, 2006.

NEVES, Abílio Afonso Baeta. Metas da atual gestão da Capes. INFOCAPES - Boletim Informativo da CAPES, Brasília, v. 3, n. 1-2, p. 14-18, 1995.

NEVES, Abílio Afonso Baeta. Depoimentos. INFOCAPES - Boletim Informativo da CAPES, Brasília, DF, v. 10, n. 4, p. 6-15, 2002.

NEVES, Clarissa Eckert Baeta; BARBOSA, Maria Lígia. Internacionalização da Educação Superior no Brasil: avanços, obstáculos e desafios. Sociologias, Porto Alegre, v. 22 , n. 54 , p. $144-175,2020$.

OLIVEIRA, Cyntia Sandes. A internacionalização do ensino superior no Brasil por meio da ação da Capes: a cocriação do programa Capes-Print. 2019. 253f. Tese (Doutorado em Desenvolvimento, Sociedade e Cooperação Internacional) - Centro de Estudos Avançados Multidisciplinares, Universidade de Brasília, Brasília, 2019.

SECCHI, Leonardo. Políticas públicas: conceitos, esquemas de análise, casos práticos. 2. ed. São Paulo: Cengage Learning, 2017.

SILVA JÚNIOR, João dos Reis; KATO, Fabíola Bouth Grello. A política de internacionalização da educação superior no plano nacional de pós-graduação (20112020). Revista Internacional de Educação Superior, Campinas, v. 2, n. 1, p. 138-151, jan./abr. 2016.

SOUZA, Celina. Políticas públicas: uma revisão da literatura. Sociologias, Porto Alegre, ano 8, n. 16, p. 20-45, jul./dez. 2006.

SPAGNOLO, Fernando. Bolsas de estudo no exterior: um programa estratégico e os ajustes necessários. INFOCAPES - Boletim Informativo da CAPES, Brasília, v. 3, n. 3-4, p. 7-17, jul./dez. 1995. 
SPAGNOLO, Fernando; CALHAU, Maria Gladis. Observadores internacionais avaliam a avaliação da CAPES. INFOCAPES - Boletim Informativo da CAPES, Brasília, v. 10, n. 1, p. 7-34, jan./mar. 2002.

SUCUPIRA, Newton et al. Parecer CFE nº 977/65, aprovado em 3 dez. 1965. Revista Brasileira de Educação, Rio de Janeiro, n. 30, p. 162-173, dez. 2005.

Texto recebido em 31/08/2020.

Texto aprovado em 17/05/2021. 